First Peoples Child \& Family Review

A Journal on Innovation and Best Practices in Aboriginal Child Welfare Administration,

Research, Policy \& Practice

\title{
Identity lost and found: Lessons from the sixties scoop
}

\section{Raven Sinclair}

Volume 3, Number 1, 2007

URI: https://id.erudit.org/iderudit/1069527ar

DOI: https://doi.org/10.7202/1069527ar

See table of contents

Publisher(s)

First Nations Child and Family Caring Society of Canada

ISSN

1708-489X (print)

2293-6610 (digital)

Explore this journal

Cite this article

Sinclair, R. (2007). Identity lost and found: Lessons from the sixties scoop. First Peoples Child \& Family Review, 3(1), 65-82. https://doi.org/10.7202/1069527ar

\section{Article abstract}

The "Sixties Scoop" describes a period in Aboriginal history in Canada in which thousands of Aboriginal children were removed from birth families and placed in non-Aboriginal environments. Despite literature that indicates adoption breakdown rates of $85-95 \%$, recent research with adults adopted as children indicates that some adoptees have found solace through reacculturating to their birth culture and contextualizing their adoptions within colonial history. This article explores the history of Aboriginal adoption in Canada and examines some of the issues of transracial adoption through the lens of psychology theories to aid understanding of identity conflicts facing Aboriginal adoptees. The article concludes with recommendations towards a paradigm shift in adoption policy as it pertains to Aboriginal children.
This document is protected by copyright law. Use of the services of Érudit (including reproduction) is subject to its terms and conditions, which can be viewed online.

https://apropos.erudit.org/en/users/policy-on-use/ 
First Peoples Child \& Family Review

A Journal on Innovation and Best Practices in Aboriginal Child Welfare

Administration, Research, Policy \& Practice

Volume 3, Number 1, 2007, pp. 65-82

\title{
Identity lost and found: Lessons from the sixties scoop
}

\author{
Raven Sinclair
}

\section{Introduction}

According to the adoption literature, transracial adoption (adoption of a child from one ethnic group into another ethnic group) usually concludes with positive adjustment outcomes for adoptees (Bagley, 1993; Fiegelman and Silverman, 1984, 1990; Bagley, Young, and Scully, 1993; Bagley and Young, 1984; McRoy, Zurcher, Lauderdale and Anderson, 1984; Simon and Altstein, 1981, 1992). The implications of these findings might be that they are applicable to all transracial adoptions and that the experience of success is life-long. Aboriginal transracial adoption, however, presents a problematic situation. Although transracial adoption in general results in positive outcomes for the adoptee and their adoptive family, for Aboriginal transracial adoptees, adoption tends to result in consistently negative outcomes (Adams, 2002; Fournier \& Crey, 1997; Bagley, 1993; RCAP, 1996; Stevanato and Associates, 1999). The success rate and outcomes in the teen years are extremely poor regardless of age of placement. For the most part, these adoptions start deteriorating relatively quickly and current statistics indicate a breakdown rate of $95 \%$ (Adams, 2002) by the time the adoptee is in the mid-teens. Of course, adoptions that do not breakdown are going to be a hidden

statistic since a forum for those statistics to be compiled has not yet been created. Exceptions to the statistics on disruption are now emerging as more research is undertaken with adults who, as children, were adopted transracially. Those 
stories are currently being told in dissertation and thesis research nation wide (Carriere, 2005; Sinclair, nd; Nuttgens, 2004; Swidrovich, 2004).

In the Aboriginal transracial adoption literature, there are factors that the research has yet to account for. These include socio-economic factors, as well as psychological, emotional, and mental factors that confront the adoptee as an adult. Most importantly, racism and racial identity issues that are alluded to in the literature are not yet adequately addressed in terms of impacts and remedial approaches. These dynamics combined create tremendous obstacles to the development of a strong and healthy sense of identity for the transracial adoptee. Although recent studies are indicating that many adoptees may develop strong identities in adulthood despite the challenges and turmoil alluded to in the literature (Sinclair, nd; Nuttgens, 2004), for the children who are currently in adoption placements or will be in the future, specific changes in adoption theory and practice are needed to address the problematics of Aboriginal adoption in Canada. The historical context of the adoption of Aboriginal children provides the framework from which Aboriginal transracial adoption has evolved.

\section{The Sixties Scoop}

The adoption of Aboriginal children in Canada between the years of 1960 and the mid1980s was first coined the "Sixties Scoop" in a report written by Patrick Johnston (1983) published as Aboriginal Children and the Child Welfare System by the federal department of Social Policy Development. Johnston undertook extensive and thorough research and his findings were vetted through the many groups that provided him with statistical data, including various levels of government, Aboriginal organizations, and band councils,
(Johnston, 2005). The term, "Sixties Scoop", was appropriate because, first, Johnston observed in the statistics that adoption as the mechanism to address problematic child welfare issues had resulted in notable increases in Aboriginal child apprehensions in the decade of the 1960s. Secondly, in many instances, Aboriginal children were literally apprehended from their homes and communities without the knowledge or consent of families and bands (Johnston, 1983 Timpson, 1995; RCAP, 1996, Saskatchewan Indian, 1977). Johnston recalled being provided with the term by a BC social worker who told him "... with tears in her eyes - that it was common practice in BC in the mid-sixties to "scoop" from their mothers on reserves almost all newly born children. She was crying because she realized -20 years later - what a mistake that had been" (Johnston, 2005).

At that point in time, Aboriginal children were apprehended in disproportionate numbers throughout Canada and adopted primarily into non-Aboriginal homes in Canada, the United States, and overseas. Approximately $70 \%$ of those children were adopted into nonAboriginal homes (Fanshel, 1972, York, 1992; Timpson, 1995; Fournier \& Crey, 1997). By the 1970s, one in three Aboriginal children were separated from their families by adoption or fostering (Fournier \& Crey, 1997). This decade marked a rapid increase in Aboriginal children in care in Canada - 44\% in Alberta, $51 \%$ in Saskatchewan, and 60\% in Manitoba (McKenzie and Hudson, 1985, p.126).

At the same time as we may be alarmed by the statistics, it is important to recognize that the "Sixties Scoop" was not a specific child welfare program or policy. It names one segment of a larger period in Aboriginal child welfare history 
where, because questionable apprehensions and adoptions figured prominently, a label was applied. The "Sixties Scoop" has evolved as a descriptor that is now applied to the whole of the Aboriginal child welfare era, simplistically defined here as roughly the time from the waning of residential schools to the mid-1980s period of child welfare devolution and last closings of Indian residential schools. Sadly, the involvement of the child welfare system is no less prolific in the current era. Dr. Lauri Gilchrist of Lakehead University noted that given current child welfare statistics, the "Sixties Scoop" has merely evolved into the "Millenium Scoop" and Aboriginal social workers, recruited into the ranks of social services and operating under the umbrella of Indian Child and Family services, are now the ones doing the "scooping".

\section{Resistance}

In 1981, a young, charismatic Aboriginal leader of the Shushwap Band in BC, Wayne Christian, was outraged at the high numbers of apprehensions and subsequent transracial adoptions of children from his own community. His efforts initiated a movement among Aboriginal leaders to voice discontent about child welfare approaches (McKenzie \& Hudson, 1985). Aboriginal people charged that government authorities were adhering to the assimilationist colonial model that assumed Aboriginal people were culturally inferior and unable to adequately provide for the needs of their children (Kimmelman, 1985; McKenzie \& Hudson, 1985; Timpson, 1995; Sinclair, Phillips, \& Bala, 1991). These authors describe the forced removal of the children as an act of genocide, which was deliberately implemented upon the demise of the residential school system to perpetuate the governments' assimilation policies (see also Chrisjohn \& Young, 1997). The UN Convention on Genocide (1948), Article 2 (e) states that "forcibly transferring children of the group to another group" constitutes the deliberate destruction of a culture, and defines an element of genocide that is punishable (UN Convention, 1948; Chrisjohn \& Young, 1997). Children were apprehended by the thousands, in questionable circumstances, with economic incentive rather than neglect or abuse emerging as the motive for removing children from their homes.

The white social worker, following on the heels of the missionary, the priest, and the Indian agent, was convinced that the only hope for the salvation of the Indian people lay in the removal of their children (Fournier \& Crey, 1997).

Economic incentive for newly established child welfare agencies fit well with ongoing government political agenda towards Aboriginal people (Fournier \& Crey, 1997). Adams (2002) elaborates, "the obscene marketing of Aboriginal children had stopped in the 1960s and 70s. These children were marketed in local newspapers and on television, but it was done in a way that did not draw attention to the government policy of assimilation". Rather, adoption was touted as a way to provide a loving and secure home for a "disadvantaged child” (Wharf, 1993; Johnston, 1983).

Resistance to child welfare involvement emerged during the Indian social movement of the 1960s that came on the heel of the 1960 Bill of Rights in Canada. Perhaps as a result of the Bill and then acquiring the franchise in 1961, Aboriginal people became more politicized in matters concerning them. Lobbying efforts of the social movement that began in the field of education with the dissemination of the position paper "Indian Control of Indian Education"1 
by the National Indian Brotherhood (1972) had a direct influence in the area of child welfare. Assuming "control" thus extended to other social spheres.

The discontent with child welfare practices vocalized by Aboriginal people across North America led to two actions that culminated in moratoria on Aboriginal transracial adoptions in the United States and Canada. In the United States, tribes forced in implementation of the 1978 Indian Child Welfare Act which disallowed the transracial placement of Indian children without band consent. In Canada, growing unrest and dissent about the transracial placement of children led to two publications that voiced the concerns of the Aboriginal population and led to moratoria on the adoption of Aboriginal children. The first, already mentioned, was Johnston's (1983) report that provided the first statistical overview of child welfare concerns pertaining to Aboriginal children. The second was a judicial review of Aboriginal adoption in the province of Manitoba led by Justice E. Kimmelman in 1985 . The report of the review was a harsh condemnation of some of the child welfare practices in apprehending and placing Aboriginal children and the province placed a moratorium on Aboriginal adoption ${ }^{2}$. Subsequently, other provinces followed suit and long-term foster care has been the norm in most provinces since that time.

\section{Colonial Context}

As we look back on that dark period in Aboriginal child welfare and critique the fact that child in care statistics increased rapidly, and many children were removed under questionable circumstances, it is important to remember the context in which the child welfare system became heavily involved in Aboriginal family life. The context referred to is the history of government-Aboriginal colonial relations, specifically, the residential school system. The ideology behind the residential school system was to "civilize" Aboriginal people and to assimilate them into the mainstream body politic (Milloy, 1999; Miller, 1996). Consquently, Aboriginal communities and families have now faced several decades of fallout from the Residential school period, which included, as by-products of an assimilationist agenda, the deliberate destruction of traditional family, social, and political systems, intergenerational abuse, and social pathology in many communities. A logical consequence of the replacement of traditional socialization with institutional abuse and trauma ${ }^{3}$ over several generations is the current high level of child welfare involvement in the Aboriginal population. Child welfare intervention that began in the late 1950s, referred to in retrospect as the Sixties Scoop, was the tip of the emerging iceberg of what is now the institution of Aboriginal child welfare. Currently, Aboriginal children are still "in care" in disproportionate numbers, but for a multitude of reasons beyond just apprehensions by "overzealous social workers"4.

A significant difference, however, exists between the Sixties Scoop era and the current "Millenium" era of child welfare. Currently, Aboriginal children are being institutionalized through long term foster and institutional care with little chance for adoption. This is perhaps the most deleterious outcome of the moratoria on transracial adoptions. Long-term childcare and foster care statistics for Aboriginal children have skyrocketed while transracial adoption statistics have plummeted. In the United States, an attempt to address this issue took place through implementation of the Multi-ethnic 
placement Act (MEPA) of 1994, along with the 1996 Removal of Barriers to Interethnic adoption (IEP) ${ }^{5}$. These pieces of legislation were designed to reduce the practice of race matching in adoptive placement and the MEPA-IEP relies on the notion that it is better for a child to be in a transracial adoptive home rather than languish in long-term foster care. The policy was designed to "eliminate discrimination in the practice of adoptive and foster care placements on the basis of race, colour, or national origin" (Adams, 2002). In Canada, no such legislation was implemented, and as a result, there are extremely high numbers of Aboriginal children in long-term foster and institutional care, with limited possibility of adoption placement. Optimistically, there is the potential that this situation will shift given a recent Saskatchewan Court of Queen's Bench ruling (December 2004) by Justice J. Ryan-Froslie, who argued that denying a child the opportunity for an adoptive home is unconstitutional6. As a result, the provincial government is in the early stages of developing strategies to address transracial adoption in ways that will meet the needs of adoptable children and First Nation communities.

\section{Repatriation}

Many transracial adoptees of the Sixties Scoop era, now adults, have encountered Aboriginal child welfare agencies as they seek to repatriate (reunite) with birth families. A large proportion of former adoptees' first point of contact is through addiction services and street agencies (Gilchrist, 1995). Many adoptees are facing identity issues because of being socialized and acculturated into a middle-class 'white' society (Hall, 1995; Gilchrist, 1995; Richard, 1998). For transracial adoptees, identity issues are exacerbated by the factors that arise in seeking out birth family and cultural ties (Fournier \& Crey, 1997; Hall, 2003). According to Bagley (1993), the crux of the issue for adoptees is being "reacquainted with the most marginalized and oppressed group within Canadian society". This, he argues, exacerbates the already problematic identity issues that Aboriginal adoptees experience.

\section{Literature on Aboriginal Adoption}

A review of adoption literature, Aboriginal transracial adoption in particular, is important in understanding how transracial adoption practice has played out and impacted on Aboriginal children. Reviewing the early literature might lead one to believe that adoption outcomes for "Indian" children were positive (Fanshel, 1972; Simon and Altstein, 1983), although Simon and Altstein (1992), in a follow-up study, concluded that Aboriginal adoptions seem to comprise a "special case". Adjustment to adoption in Aboriginal children appears to deteriorate as the children get older, with a reported adoption breakdown rate of $85 \%$ (McKenzie and Hudson, 1985) with Adams (2002) noting that rate is as high as $95 \%$. No studies examine the experiences or long-term adjustment of Aboriginal adults who were transracially adopted as children (Jaffee and Fanshel, 1970; Bagley and Young, 1981: Hall, 2003). The most recent research and literature on Aboriginal adoption express growing concerns about the damaged self-esteem and identity confusion in Canadian adolescent Aboriginal adoptees (Bagley, 1993; Hall, RCAP, 1995; Stevenato and Associates, 1998, 1999; Adams, 2002). The voice of adult Aboriginal transracial adoptees has been absent in the literature, with the exception of a small body of grey literature that can be found on the internet (see, for example The Aboriginal Adoptee website at http://www. 
ncf.carleton.ca/ de723/adoptee.html). There are also an increasing number of dissertations and Master's theses recently completed by and with Aboriginal adoptees across Canada and the United States (Carriere, 2005; Sinclair, nd; Nuttgens, 2004; Swidrovich, 2004).

Within the early literature, quite outdated at this point, the political agenda was evident in the unequivocal support of Aboriginal transracial adoption (Lyslo, 1960, 1961). Fanshel's (1972) Far from the Reservation, study examined the experiences of 97 adoptive families. The Bureau of Indian Affairs as well as the Child Welfare League of America, which wanted to promote the Indian Adoption Project, funded this study. Although the authors hypothesize that parents who adopted transracially would be politically more liberal than same race adoptive parents, it appears that the true intention of the study was to promote the adoption project itself. A summary of the project reported, "It has been gratifying to see the opportunities afforded these Indian children through adoption, as well as the full acceptance which they have received" (p.18).

The fact that the creators of the Indian Adoption project commissioned Fanshel's study makes the results of the study questionable, as is the author's reference to the money saving aspects of adoption. He notes that each adoption saved the government $\$ 100,000$ per child, who would have otherwise ended up in foster care or a boarding school.

The study also implicates negative social attitudes. Fanshel gathered demographic data on Aboriginal birth mothers based on adoption agency data. Fanshel states that "almost 45\% were described in terms which indicated that they suffered from quite severe personality disorders", although out of 95 birthmothers, only 3 had self-identified as having mental health problems (p.59). This type of reporting in research seems more indicative of racial bias than valid research.

The evidence of prejudice in studies is frightening in its implications for Aboriginal adoptees, particularly when the bias is evident from the responses of adoptive parents. Simon and Altstein (1992) questioned parents about their child identifying with their Aboriginal culture. One couple responded that it was unlikely their child would identify with their culture because "there is no contemporary American Indian culture..." (p.88) [emphasis is mine]. Such an attitude might have serious consequences for a child's ability to identify with and feel positively about their ethnicity given the implication that a parent who holds the belief that there is no Aboriginal culture is highly unlikely to be able or willing to teach the child anything about that culture. Conversely, several studies found that a positive parental attitude towards the child's ethnic group, as well as some form of social involvement with that ethnic group in the family's life, is significantly correlated with a child's positive adjustment and positive sense of ethnic identity (Ladner, 1977; Morin, 1977; McRoy and Zurcher, 1983, 1984: Lee \& Quintana, 2005).

Christopher Bagley, an adoption researcher out of Canada, found in many studies that outcomes for transracial adoption are generally excellent. He noted, however, that outcomes for Aboriginal adoptees in Canada were distinct from the norm. Bagley's (1993) research on Aboriginal transracially adopted youth concludes that outcomes for this group were extremely poor. Bagley suggested that, as the result of widespread discrimination and prejudice, adoptive parents cannot transmit 
an adequate sense of ethnic identity to their children. This concept is supported in several studies that theorize that adoptive parents cannot adequately role model coping skills for the discrimination that adoptees face in society (Bensen, 2001; Triseliotis, 1989); skills which may be vital for minority adopted children (see also Kim, 1978). Bagley's study found that by the age of $15,20 \%$ of the Aboriginal adoptions had broken down, and two years later this figure had risen to $50 \%$. He found that Aboriginal youth had extremely poor self-esteem and an extraordinarily high rate of suicidal ideation. Aboriginal adoptees who did not exhibit any outward signs of behavioral or emotional problems, also scored lower on measures of self-esteem and higher on suicidal ideation scales (p.26). Significantly, he found that nonadopted Aboriginal youth had self-esteem rates comparable to non-adopted white youth. From this study, we can infer that something intrinsic to transracial adoption merits scrutiny.

Bagley's work provides a vital reference point for research on adult Aboriginal adoptees. The research supports what is common knowledge among Aboriginal people, adoption workers and others who have been exposed to Aboriginal adoptions over time; that for Aboriginal children, adoption is problematic. One Aboriginal scholar, in a doctoral study of street youth, found that the majority of the homeless Aboriginal street youth that she encountered were Aboriginal adoptees (Gilchrist, 1995). Kenn Richard, the Executive Director of Toronto Native Child and Family Services, has expressed his concern for years about the high number of adoptees who come to agency in crisis (1998). Informally, those involved in the adoption field know that the levels of substance abuse, homelessness, incarceration, and suicide among adoptees in the last thirty years have been alarming.
Racial and racial identity issues discussed sparingly in the research shed some light on the challenges facing Aboriginal adoptees and serve to highlight that attention to the area of transracial identity development is needed. Hayes (1993) criticizes the measures used in many studies of transracial adoption as inadequate and unable to "get at the richness and complexity of a sense of identity" (p.303). It is this complexity that contemporary studies need to theorize about and address. For example, Bausch and Serpe (1997) in their study of transracial adoptees who exhibit high levels of discomfort with their physical appearance or racial heritage, theorize that this is largely attributable to the fact that most adoptees live in predominantly white neighborhoods and are, therefore, isolated from inter-ethnic contact. From studies like this (and Kim, 1978), we can glean some understanding of the transracial adoption experience and identity conflicts for adoptees.

\section{Theorizing about Identity Conflict}

The lack of literature and research in the area of Aboriginal adoption means that to this point we rely largely on common knowledge in order to influence policy and develop programs for adoptees. There are some answers to be gleaned from contemporary literature in the social sciences, particularly psychology and race theory, as to why the transracial adoption of Aboriginal children, in particular, is problematic. Bagley (1993) was perhaps exceedingly accurate to articulate that systemic racism and the general denigration of Aboriginal culture may provide impossible socio-cultural contexts for adoptees.

Identity is an extremely tumultuous journey for all adoptees (Sorosky, Baron, \& Panner, 1975). Developing a cultural identity related 
to one's biology when raised in a different cultural context is exceedingly difficult. In contemporary society, there are very few redeeming characteristics attributed to "Aboriginality". The Canadian ethos has been that Canada is not a racist country and racism does not occur. Indeed, Canada has been very proud of its international reputation as a land of equality. Unfortunately, people who live on the other side of the "colour line" in Canada have a different perspective (Frideres, 2001). Adoptive parents who buy into a belief that racism does not exist may not be able or willing to prepare a child to deal with issues that "do not exist." The child, who may experience racism and discrimination in their social encounters will learn quickly that their experiences do not necessarily match with what they are told or what they have been socialized to anticipate that life will be like. They may believe that they are inherently "different" because they know that their parents and family do not experience those same things (Kim, 1978). Rue \& Rue (1984) astutely recognize the challenge of racism for the adoptee:

"Racism, even its non-violent forms, is still pernicious. The difficult thing about racism in our particular situation is that when it is directed at [our adopted son] Carl, he must deal with it alone. He does not have the comfort of knowing that the rest of the family shares in his experience. If we were an entire family of minorities, his situation would be much different in this respect. And [sic] since neither of us has ever been the victim of racial prejudice, we are ill-prepared to help him develop the skills useful in combating it (p.249).

Further, an adopted child who experiences racism and discrimination may not share that with their family because it is not part of their family ethos. Kim (1978) explains that for a child who wants to fit in, bringing in information that highlights their difference might be emotionally challenging. The family provides an element of safety; a secure enclave from their experiences of the outside world. This redeeming factor for the transracial adoptee may, however, also be the source of tremendous conflict. Once the adoptee leaves the enclave of their adoptive home environment, unless they have learned to adequately cope with the realities of being an Aboriginal person in this country, they may find their identity to be a source of conflict.

Many adoptees experience a lack of cultural mirrors in their adoptive social environments. Within their adoptive context, their roles and expectations are understood, and most likely, there is no aura of 'otherness' surrounding their existence. However, once they walk out the door, their social status alters drastically, as do the expectations of them and the treatment accorded them by others. The adoptee may eagerly and readily embrace and adapt to the culture of their adoptive family, but socially, they may be excluded from enacting that culture and those roles out in the social arena.

The adoptee, like any child, does not question their socialization; they just live it. Many adoptees are raised in an environment of privilege, power, and status (Sinclair, nd; Nuttgens, 2004, Swidrovich, 2004). Their economic status may be higher than the average "white" person and yet they do not carry that status on their own. At some point, they are inevitably forced to confront a socially ascribed inferior status associated with their ethnic minority group (Kim, 1978). Not only are Aboriginal adoptees' ethnic and cultural identity wrapped up in cultural stigmatization, 
their identities are most likely associated with poverty, alcoholism, and other negative stereotypes. The conflict that results from the need to constantly adapt is likely a source of angst from which many adoptees engage in destructive and harmful behaviours to themselves, their adoptive family, and their environment (see, for example, Adams 2002; Gilchrist, 1995). For many adoptees, the tensions have led to incarceration, substance abuse, or suicide7. Recent Corrections Canada data indicates that $63 \%$ of Aboriginal offenders stated that they were adopted or in foster care (Trevethan, Moore, Auger, Macdonald \& Sinclair, 2005).

In response to the growing awareness of identity conflicts in Aboriginal adoptees, adoption agencies and adoptive families sought to find solutions. Some of conventional adoption literature emphasizes the importance of instilling a cultural heritage in the child through books, movies, and culturally relevant events such as pow wows (Adams, 2002). Unfortunately, these are idealized versions of Aboriginal culture and not realistic as means for instilling identity. What the child sees when they venture out into the world as an adult is not necessarily going to match with idealized versions of Aboriginal culture. Indeed, chances are high that what they observe will more readily match the negative stereotypes learned in the course of their daily lives through media and education. What child is going to want to identify with negative stereotypes; the derogatory names they have been called, the destitute individual on the street? What the adoptee may not know is that they are not seeing Aboriginal culture; they are seeing the vestiges of colonization and a neo-colonial society's construction of Aboriginal culture. However, who is available to explain that context to them?
There are aspects of some social and human behaviour theories that can assist in contextualizing and understanding the experiences and the negative reactions of Aboriginal adoptees.

\section{Contemporary Theoretical Links}

Socialization, according to Kim (1978) refers to "the process [that] enables individuals to participate effectively as members of interest groups, local communities, and larger society". Kim says that, according to Erickson, identity crisis in socialization consists of people asking the question "who am I?" Erickson argued that this is a crucial developmental task during adolescence and was the "final establishment of a dominant positive ego identity" (p. 306). Without this development, one will confront identity diffusion. Young (1969) adds "as racial and cultural minority group members, minority children have more and more particular difficulties in defining a positive identity because minority status carries with it goal restriction." (p.1103). Ascribed inferior status and negative stereotyping occurs in the forms of name-calling and social exclusion. The most insidious problem, however, is the compounding of daily prejudice and rejection with "the pervasive restraining force operating in parts of American society, which is now commonly called institutional racism" (Young, 1969). These socialization dynamics relevant to minority people are essential in understanding transracially adopted Aboriginal children and youth who grow and develop in unique contexts. The unique context is described by Kim (1978) as a paradox. "Adoptive parents are faced with a dilemma; they have the contradictory task of incorporating a child fully into a family and simultaneously promoting a sense of distinct ethnic identity. The very "success" of transracial 
adoption, is indicative of its failure as this success has been achieved at the expense of the development of an ethnic identity" (p.485).

We can understand more clearly the dilemmas and paradoxes facing adoptees by looking at the assertions of various social theorists including Kohlberg, Ericsson, Mead, and Cooley. For example, Kohlberg's model of moral development (Schriver, 2001) includes a stage that refers to "maintaining the good relations and the approval of others", while Erickson's epigenetic model, stage six, discusses competence as arising out of "identification with and acceptance of peers". In a social context where discrimination may be a regular occurrence, the problem for the Aboriginal adoptee is how to achieve 'good relations', 'approval', and 'acceptance' of others when racial exclusion is the norm. If a child is deemed deficient by virtue of their ethnicity, the chances are high they will be excluded and ostracized by peers. According to Ericsson, failure to achieve these goals leads to feelings of inferiority and incompetence. Of course, Ericsson's theory and other conventional theories of human development do not include ethnicity as a consideration.

[Ethnicity] may be especially significant if we are attempting to develop a positive sense of who we are in the context of a hostile environment. Such a hostile environment exists for many members of the diverse groups with which we are concerned as social workers (Schriver, 2001, p.251).

One of the mitigating factors for minority children existing in a 'hostile environment' is the comfort afforded by close contact with family, friends, and their community. In this safe context, children can develop strong and positive self-identification. Aboriginal adoptees, however, usually do not have the safety nor security of an enclave afforded by same-race relatives and community, but as indicated, a safe, nurturing and positive adoption context may provide the necessary comfort and contradiction.

A final theory that lends a great deal of insight into the world of the Aboriginal transracial adoptee is symbolic interaction. Symbolic interaction holds that "people are seen first and foremost as beings who interact with one another based on shared meanings and symbols. Thus human interaction is symbolic interaction" (Robbins, Chatterjee \& Canda, 1998, p.268). People assign social meanings to their experiences, and human behaviour is a function of social behaviour. Cooley (cited in Robbins, Chatterjee, \& Canda, 1998) theorized that we are dependent upon the reflections that we receive in interactions with others and from them we make judgments of ourselves. If reflection, according to Symbolic interactionists, is the means by which we come to our self-concept and self-conceptions, the implications for Aboriginal adoptees are quite frightening. If we create meanings and symbols in our interactions with other people, what happens when those meanings and symbols are constantly changing, or worse, primarily negative? For Aboriginal people in Canada, social interaction is, at times, a guessing game. Young argues that "only rarely does a child of minority status escape the damaging effects of racism" (p.43). One individual may be extremely friendly and engaging, and the next individual may be blatantly hostile, contemptuous, and even violent. For the Aboriginal adoptee that is in their formative years, it would be difficult to create, and then rely upon, consistent interpretations of meanings and symbols in that social environment. 
In the context of these contemporary theories of human behaviour and social development, the traumatic experiences of adoptive families (see for example, Adams, 2002) who adopted Aboriginal children may be more easily understood8. These theories help us to understand the behaviours in terms of the mental and emotional turmoil that would result as the individual attempts to develop a sense of identity and self-concept.

In the final analysis, one might assume from these discussions that, generally speaking, Aboriginal adults adopted as children would be terribly maladjusted. It is true that in some instances adoptees have suffered horribly. It is also true that in other instances, they have not. Aboriginal adoption outcomes fill the entire spectrum from deleterious outcomes that include homelessness, addictions, incarceration, and suicide, to successful outcomes that include economic and academic achievement, happiness and contentment.

\section{Adult Adoptees}

A recent doctoral research project is finding that many adult Aboriginal adoptees, some of whom experienced adoptions fraught with abuse and trauma, have developed exceedingly strong and well-articulated identities (Sinclair, nd) while other studies indicate that many adoptees are content with their adoptive experiences (Nuttgens, 2004; Swidrovich, 2004). The preliminary findings of the study indicate that despite sometimes horrific stories of familial and social trauma, many adult Aboriginal adoptees express contentment with their current lives, have deep and meaningful insight into the social and psychological dynamics of Aboriginal adoption, and are exceedingly socially capable. The majority of adoptees in this study $(\mathrm{N}=17)$ are employed in professional capacities, are well educated, lead stable lives, and are exceptionally attentive parents to their children. Some report difficulties in dealing with emotional upheavals as adults and many identify relationship difficulties as a consequence of their adoptive experiences. However, many adoptees also acknowledge having acquired advantages as the result of being adopted. Some of the advantages include being able to traverse both Aboriginal and 'white' worlds with ease, a sense of personal efficacy in terms of education, and career and economic success (Sinclair, nd).

The question is, therefore, why are the majority of adult adoptees in current research reporting successful life outcomes despite the reported problematics of Aboriginal transracial adoption in the context of the Sixties Scoop? Sampling bias may be an obvious answer but even amongst these "success stories", we see evidence of traumatic identity crises, psychological trauma, and behavioural problems. Many adoptees suffered extreme forms of abuse. Many marvel at their very survival.

Obviously more research is needed. Resiliency amongst Adoptees is an area that beckons inquiry. The influence of repatriation to birth culture is another that needs exploration. It appears that many adoptees, at some point along their journey, found a level of truth and certainty within Aboriginal culture that provided a critical source of healing and renewal (Sinclair, nd; see also Nuttens, 2004; Stolen Generations, nd). Perhaps by reconnecting with their birth culture, the individual provided for themselves vital cultural mirrors necessary for self-validation; a cultural reframing from which to review and re-perceive their experiences. From this perspective, many adoptees learned about their adoption experiences in the context of Canadian colonial history which, for many, was a powerful catalyst for reframing 
their personal experiences (Sinclair, nd). In this study, some of the participants were, for the first time, able to perceive their experiences as a socio-political act rather than as a consequence of personal deficiency. Relieved from a burden of self-blame, many adoptees have integrated a unique self-based identity that is, of course, relative to their own context and experiences and some adoptees have unique perspectives of their identities as multi-faceted and multi-cultural (see Nuttgens, 2004; Stolen Generations, nd). Indeed, there is no single group identity label or theory that can be applied to adoptees of the Sixties Scoop as a whole. Although there are some personality and identity characteristics that many adoptees share as the result of the similarity of their experiences, each individual's sense of identity is unique and derived from their own combination of experiences and perspectives (Sinclair, nd; Nuttgens, 2004). Each adoptee in the stated study, despite the losses and traumas experienced, found and created their own cultural and identity niche.

As we close the door on the "Sixties Scoop" and struggle to not perpetuate the status quo in the Millenium era of child welfare with Aboriginal populations, we must reflect on the lessons of the past. Despite the evidence of tremendous resilience in the human spirit that has allowed many adoptees to survive and thrive, children will always deserve the highest level of protection and consideration. As the result of the concerns raised in reviewing the literature, and the stories shared by adoptees, there are several recommendations for changes in policy and perspective of Aboriginal transracial adoption in Canada.

\section{Towards a Paradigm Shift in Aboriginal Transracial Adoption Ideology}

There are three recommendations (Sinclair, nd) for approaching Aboriginal transracial adoption issues. They include taking an ideological stance that incorporates a cultural-racial identity matrix; rejecting the myth that cultural and ethnic heritage can be instilled through books and pow wows; and constructing a bi or multi-cultural family stance which, in effect, reconstitutes the cultural entity of the entire adopting family identity.

Baden (2002) presents a racial-cultural identity matrix as a method of helping transracial adoptees assess their own cultural identity. In a research study of cultural identity, Baden stated that the findings of her study indicate that "heterogeneity exists among transracial adoptees and because a particular way or ways of identifying was not associated with better or worse psychological adjustment. Neither the proponents or opponents can purport a "best way" to identify as a transracial adoptee" (p.189). This is very interesting because this model is a cultural-racial identity matrix. There is no identification dichotomy facing adoptees, i.e. that the adoptee must choose either their birth identity or their adoptive identity. There are enough factors in a cultural-racial matrix from which to choose so that the individual will fit somewhere within the multi-dimensional continuum without being pathologized and without having to alter their identification to fit the model. Adoptees do have a cultural identity; it is a unique mix of their birth heritage, the adoptive heritage, combined with their personal experiences, choices, and understandings of the environment. An approach that honours the multi-faceted nature of adoptee identity will be a welcome shift. This approach is personfocused rather than ideologically focused. In terms of intervention, the model could help social workers to "start where the adoptee is at" in terms of their unique cultural identity.

The second recommendation is to completely do away with the myth that cultural and ethnic 
heritage can be instilled through books and weekend cultural activities. Repeatedly, the literature suggests that exposing the adoptee to their culture through pow wows and books and cultural camps, will alleviate their distress. In fact, there is likely the risk that these acts only contribute to conceptions of "otherness" and difference, not only from the birth culture but also from the adoptive family. Approaching culture in this way will lead the individual to learn about the façade of the culture, not the culture as it actually exists. Adoptees who are now adults suggest that birth family, including extended birth family, and birth culture contact during their formative years might have helped alleviate the sense of difference and the cultural isolation that many of them experienced (Sinclair, nd). These notions lend support to exploring the benefits and drawbacks of open adoption for Aboriginal children. At the very least, new directions must be taken in preparing adoptive families to meet the needs of their Aboriginal child. Indeed, in order for a child to learn about their culture, the people most significant to them must also learn about the culture. This leads to the third recommendation.

The third recommendation is the concept of constructing a "bicultural family" or "multicultural" identity. This requires a paradigm shift in the perspective of adoption personnel and potential adoptive families. This perspective may be essential to the well being of Aboriginal transracial adoptees. In one study, the third group in the three groups of families studied described themselves as "bicultural" as the result of bringing an interracial child into their home (McRoy, Zurcher, Lauderdale and Anderson, 1984). Rue \& Rue (1984) articulated the same concept. "When the Rue family decided to adopt a child from Thailand, they immediately conceived of themselves as a
Thai-American family". The generally accepted, indeed unquestioned, perspective taken by social workers and prospective adoptive families has been that the child is to be integrated into the adoptive family; the 'minority' is absorbed into the 'majority'. Adoption ideology has never assumed that because the child of one ethnicity will be entering into a family of another culture, that the whole family becomes a blend of all the cultures involved. However, the implications of an adoptive family taking on a bicultural identity as opposed to the child standing alone in their "transraciality" might be significant. Such a paradigm shift might influence how an adoptive family conducts itself with respect to their adopted Aboriginal child including, for example, where they live, their choice of schools, and their general family "culture". At a policy level, such an ideological shift might influence adoptive parent/family screening strategies as well as general transracial adoption procedures, specifically in terms of adoptive family preparation.

\section{Conclusion}

According to the literature, although transracial adoption results in positive and favourable outcomes for both child and family, Aboriginal transracial adoption has been a notable exception. The statistics indicating a high breakdown rate are frightening for adoptive families who have a young Aboriginal adopted infant or child because, if the statistics hold true, chances are very good that by the time that child reaches adolescence, the family will encounter serious complications. The question of why Aboriginal adoption results in poor outcomes can be understood from the perspective of several cotemporary theories of human and social development. Symbolic interaction, in particular, provides several key concepts and 
perspectives to understanding the conflict and turmoil that adoptees experience. The literature helps one understand the tremendous challenges for an Aboriginal child in North America to develop a healthy identity and sense of self in the current ideological and social context. The denigration of Aboriginal culture and racism abound in both subtle and blatant ways for Aboriginal people. For Aboriginal adoptees, in particular, these experiences may be a harsh contrast to their experience of a safe, privileged non-Aboriginal environment. For Aboriginal adoptees, they must deal with the contradictions of being a member of the marginalized group, despite having a socialization, identity, and role expectations of the dominant group.

Although Aboriginal transracial adoption results in both positive and negative outcomes, recent research appears to be indicating that many Aboriginal adult adoptees from the era of the Sixties Scoop and beyond have developed strong and positive identities despite, or in spite of, the challenges of their experiences (Carriere, 2005; Sinclair, nd; Nuttgens, 2004; Swidrovich, 2004). Hence, it is apparent that some of the long-term outcomes for Aboriginal transracial adoption contradict the statistics contained in the literature. Many adoptees do recount difficult and traumatic adoption experiences and the turmoil seems to manifest in the teenage years and in young adulthood. As more research is completed, we are hearing stories from the other end of the spectrum. According to the emerging research, we can conclude that in many instances transracial adoption can have positive and successful long-term outcomes, and that Aboriginal cultures in Canada are sources of solace and healing for adoptees. Adoptees who choose to reacculturate to their birth culture, find needed belonging and cultural validation. The act of repatriation often assists adoptees in reframing their experiences within the context of Canadian colonial history. The adoptees, insightful of the transracial adoption experience, concur that changes must take place in the adoption field and they are supportive of further research in the area. The recommendations provided in this article are based upon the small emerging body of research on Aboriginal transracial adoption, combined with information collected in stories, newspaper articles, and grey literature. How these recommendations manifest in policy and practice will depend upon the quality of collaboration amongst the stakeholders in transracial adoption. It is suggested that Adult adoptees will be the best source of information to direct the future of adoption research and policy.

In closing, it is not the contention of this article that Aboriginal transracial adoption should not take place. It would be naïve to place the blame for current child welfare involvement solely on government and child welfare authorities. In the context of historical colonial policies of assimilation that saw child welfare intervention follow upon the heels of the residential school system, the extensive involvement of child welfare authorities into Aboriginal lives is more clearly understood. Aboriginal communities now recognize that the responsibility for child welfare outcomes from this point forward rests with Aboriginal communities who have fought long and hard to have control of child welfare. In an ideal world, all Aboriginal children will remain with their families of origin. Until that happens, Aboriginal communities, child welfare agencies, and families will continue to make decisions to place children for adoption transracially, because those decisions are sometimes made in the best interests of the child. However, we do not need to perpetuate the wrongs of the past. As we look forward from 
the Sixties Scoop and learn the lessons of that era, the field of social work must be proactive, adaptive, and creative. With core changes in Aboriginal transracial adoption ideology, it is asserted that policies and practices will follow suit, to the benefit of adoptive families and, most importantly, Aboriginal children.

\section{Endnotes}

1. The position paper asserts, "Unless a child learns about the forces which shape him: the history of his people, their values and customs, their language, he will never really know himself or his potential as a human being." See http:// www. afn.ca/article. asp? $\mathrm{id}=830$.

2. The report refers to W. Christian's statement that 150 children were removed from his band of 300 over a period of 25 years. In 1995, the author was privy to viewing the A-list, (a record of status children adopted) for one band in Manitoba where over a period of several years, almost every child had been apprehended and adopted.

3. It is important to note that not all residential schools perpetrated abuse and trauma. For more information, see either Miller (1996) or Milloy (1999).

4. For a comprehensive look at Aboriginal Child Welfare literature, see Bennett, Blackstock, \& De La Ronde's (2005) literature review and annotated bibliography http://www.fncfcs.com/ docs/AboriginalCWLitReview_2ndEd.pdf.

5. For more information on the MEPA-IAP, see http://www.ssw.umich.edu/tpcws/articles/legal_ MEPA.pdf.

6. For a summary of the case, see http://www. lawsociety.sk.ca/judgments/2004/QB2004/ 2004skqb503.pdf and for a discussion of the implications, see http://www.adoption.ca/news/ 050105sk.htm.

7. In my casework in Aboriginal adoption repatriation, a disproportion number of inquiries came from adults incarcerated in prisons in the U.S.
8. Adams' stories recount some experiences of children who are Fetal Alcohol affected. It's beyond the scope of this article to delve into FASD and its relationship to adoption outcomes/success, but it is clear that FASD can play a significant role in Adoptions.

\section{Bio}

Raven Sinclair is a member of Gordon's First Nation of the Treaty \#4 area of southern Saskatchewan. She has a BA in Psychology from the University of Saskatchewan, a Certificate and Bachelor's degree in Indian Social Work from the First Nations University of Canada, and an MSW from the University of Toronto. She is currently a Ph.D. Candidate in the Faculty of Social Work at the University of Calgary. Raven's interests include Indigenous knowledge and research methodologies, the synthesis of traditional and contemporary healing theories and modalities, Aboriginal cultural identity issues, colonial theory, and concepts in decolonization. Raven is a the Assistant Director of the Indigenous Peoples' Health Research Centre and an Assistant Professor of Social Work with the Faculty of Social Work, University of Regina, Saskatoon Centre.

\section{References}

Adams, M. (2002). Our son a stranger: Adoption breakdown and its effects on parents. Montreal: McGill-Queen's University Press.

Baden, A. (2002). The psychological adjustment of transracial adoptees: An application of the cultural-racial identity model. Journal of Social Distress and the Homeless, Vol. 11(2). April 2002. 167-191.

Bagley, C. (1993). Transracial Adoption in Britain: A follow-up study, with policy consideration. Child Welfare, 72 (3), May-June 1993, 285299.

Bagley, C., Young, L., \& Scully, A. (1993). International and Transracial Adoptions: A mental health perspective. Newcastle upon Tyne: Althenaeum Press Ltd. 


\section{Identity lost and found: Lessons from the sixties scoop}

Bagley \& Young, L. (1984). The long-term adjustment of a sample of inter-country adopted children. International Social Work $23,16-22$.

Bausch, R.S., \& Serpe, R.T. (1997). Negative Outcomes of Interethnic Adoption of Mexican American Children. Social Work, 42 (2), March 1997, 136-143.

Benson, R. (Ed.)(2001). Children of the dragonfly: Aboriginal American voices on child custody and education. Tuscon: The University of Arizona Press.

Bennett, M., Blackstock, C. \& De La Ronde, R. (2005). A Literature Review and Annotated Bibliography on aspects of Aboriginal Child Welfare in Canada. 2nd Edition. Available at First Nations Child and Family Caring Society website http://www.fncfcs.com/docs/ AboriginalCWLitReview 2ndEd.pdf.

Canada. Royal Commission on Aboriginal Peoples. (1996). Available from http://www. ainc-inac.gc.ca/ch/rcap/sg/ci2 e.pdf.

Carriere, J. (2005). Connectedness and Health for First Nation Adoptees. Unpublished Doctoral Dissertation, University of Alberta.

Fanshel, D. (1972). Far from the Reservation: The transracial adoption of American Indian Children. New Jersey: The Scarecrow Press, Inc.

Brodzinsky, D., \& Schechter, M.D., (1990). The Psychology of Adoption. New York: Oxford University Press. 187-200.

Feigelman, W., \& Silverman, A.R. (1984). The long-term effects of transracial adoption. Social Service Review, 48, 588-602.

Fournier, S. \& Crey, E. (1997). Stolen from our embrace: The abduction of First Nations children and the restoration of Aboriginal communities. Vancouver: Douglas \& McIntyre.

Frideres, J. \& Gadacz, R. (2001). Aboriginal Peoples in Canada: Contemporary conflicts. Toronto: Prentice Hall, 2001.

Gilchrist, L (1995). Aboriginal Street Youth in Vancouver, Winnipeg and Montreal. Unpublished doctoral dissertation. University of British Columbia. 1995.

Hall, L. (2003) Personal Communication. March 4, 2003.

Hall, L. (Speaker - Vancouver, BC 93-06-02 13) (1995). For Seven Generations: An Information Legacy of the Royal Commission on Aboriginal Peoples. Libraxus Inc.

Hayes, P. (1993). Transracial adoption: Politics and ideology. Child Welfare, Vol. 62(3). MayJune 1993; 301-310.

Jaffee, B. \& Fanshel, D. (1970). How they fared in Adoption: A Multinational Perspective. New York: Columbia University Press.

Johnston, P. (2005). Personal email communication with Raven Sinclair, December 8, 2005.

Johnston, P. (1983). Aboriginal children and the child welfare system. Toronto: Canadian Council on Social Development.

Kim, D. (1978). Issues in transracial and transcultural adoption. Social Casework, Vol. 59(8), October, 1978, 477-486.

Kimmelman, Justice E.C. (1985). No Quiet Place: Review Committee on Indian and Metis Adoption and Placements. Manitoba Community Services.

Ladner, J. (1977) Mixed Families: Adopting across 
racial boundaries. London: Doubleday.

Lee, D. \& Quintana, S. (2005). Benefits of cultural exposure and development of Korean perspective-taking ability for transracially adopted Korean children. Cultural Diversity and Ethnic Minority Psychology, Vol. 11(2), May 2005, 130-143.

Lyslo, A. (1961). Adoptive Placement of American Indian Children with Non-Indian Families. Child Welfare, 40(5), May 1961, 4-6.

Lyslo, A. (1960). Adoption for American Indian Children. Child Welfare, 39(6), June 1960, 32-33.

McRoy, R., Zurcher, L, Lauderdale, M., \& Anderson, R. (1984). The Identity of Transracial Adoptees. Social Casework: The Journal of Contemporary Social Work, 65, 34-39.

McRoy, R. \& Zurcher, L. (1983). Transracial and Interracial Adoptees: The adolescent years. Springfield: Charles C. Thomas.

Miller, J. R. (1996). Shingwauk's Vision: a history of native residential schools. Toronto: University of Toronto Press.

Milloy, J. S. (1999). A National Crime: the Canadian government and the residential school system, 1978-1986. Winnipeg, University of Manitoba Press.

Morin, R. (1977). Black child, white parents: a beginning biography. Child Welfare, 56, 576583.

National Indian Brotherhood. (1972). Indian Control of Indian Education: Policy paper presented to the Minister of Indian Affairs and Northern Development. Full text available at http://web.uvic.ca/ablo/ documents/IndianControlofIndianEducation. pdf.

(C) Raven Sinclair
Nuttgens, S. (2004). Life Stories of Aboriginal Adults Raised in NonAboriginal Families. Unpublished dissertation. Faculty of Graduate Studies and Research, University of Alberta. Edmonton, Alberta. Spring 2004.

Richard, K. (1998). A submission on the matter of cross cultural Aboriginal adoptions. Paper submitted to the British Columbia Human Rights Tribunal.

Robbins, S., Chatterjee, P., \& Canda, E. (1998). Contemporary human behaviour theory: A critical perspective for social work. London: Allyn and Bacon.

Rue, M. \& Rue, L. (1984). Reflections on bicultural adoption. In Bean, P. (184) Adoption: Essays in social policy, law, and sociology. New York: Tavistock Publications.

Saskatchewan Indian. (1977). Indian Children Taken Illegally. January, 1977, Vol. 7(1). P.11. Available at http://www.sicc.sk.ca/saskindian/ a77jan11.htm.

Schriver, J. (2001). Human behaviour and the social environment: Shifting paradigms in essential knowledge for social work practice. 3rd ed. London: Allyn and Bacon.

Silverman, A and W Feigelman (1990): Adjustment in interracial adoptees: An overview. I: Brodzinsky, D (Ed), The Psychology of Adoption. New York: Oxford university Press.

Simon, R. \& Alstein, H. (1992). Adoption, race, and identity: From infancy through adolescence. New York: Praeger Publishers.

Simon, R. \& Altstein, H. (1981). Transracial adoption: A follow-up. MA: Lexington Books.

Sinclair, Judge M., Phillips, D. \& Bala, N. (1991). Aboriginal Child Welfare in Canada. In Bala, 
Identity lost and found: Lessons from the sixties scoop

J., Hornick, J.P., \& Vogl, R. (1991). Canadian Child Welfare Law: Children: Families and the State. Toronto: Thompson Educational Publishing Inc., pp. 171-194.

Sinclair, R. (nd). Adult Aboriginal Transracial Adoption: A critical case study of cultural identity. Unpublished doctoral dissertation. In Progress. University of Calgary.

Sorosky, A., Baron, A., \& Pannor, R. (1975). Identity Conflicts in Adoptees. American Journal of Orthopsychiatry, 45(1), January, 18-27.

Stevenato and Associates, J. Budgell. (1999). Our Way Home: A report to the Aboriginal Healing and Wellness Strategy on the repatriation of Aboriginal people removed by the child welfare system. Toronto: Author.

Stevenato and Associates, J. Budgell. (1998). Aboriginal Healing \& Wellness Strategy Research Project: Repatriation of Aboriginal Families. Toronto: Author.

Stolley, K. (1993). Statistics on adoption in the United States. The Future of Children Adoption [Online], 3, 26-42. Available at http://www.futureofchildren.org/.

Stolen Generations. (nd). Book of Voices. Winnipeg, Manitoba: Author.

Swidrovich, C. (2004). Positive Experiences of First Nations Children in non-Aboriginal Fosteror Adoptive Care: Deconstructing the “Sixties Scoop." Unpublished MA Thesis. College of Graduate Studies, University of Saskatchewan. Saskatoon, Saskatchewan. December 2004.

Timpson, J. (1995). Four decades of literature on Aboriginal Canadian child welfare: Changing themes. Child Welfare, Vol. 74(3), 525-546.

Trevethan, S., Moore, J., Auger, S., Macdonald,
M, and Sinclair, J. (2005). Childhood Experiences affect Aboriginal Offenders. Correctional Service of Canada. Available at http://www.csc-scc.gc.ca/text/pblct/forum/ e143/e143c e.shtml.

Triseliotis, J. (1989). Some moral and practical issues in adoption work. Adoption and fostering, Vol. 13(2), 21-27.

United Nations. (1948). Convention on the Prevention and Punishment of the Crime of Genocide. Adopted by Resolution 260 (III) A of the United Nations General Assembly on 9 December 1948. Available at http://www.hrweb.org/legal/genocide. $\underline{\text { html\#Article\%202.5. }}$.

Webber, M. (1998). As if kids mattered: What wrong in the world of child protection and adoption. Toronto: Key Porter Books Ltd.

Wharf, B. (Ed.)(1993). Rethinking Child Welfare in Canada. Toronto: McClelland and Stewart.

York, G. (1992). The Dispossessed: life and death in native Canada. Toronto: Little, Brown (Canada) Ltd.

Young, D. (1969). The socialization of American minority people. Goslin, D. Handbook of socialization: Theory and research. Chicago: Rand McNally and Company. 